ISSN: 0213-1854

\title{
Mitos del tiempo: exilios y retornos en la poesía de Luis Cernuda
}

(Myths of time: exiles and returns in the poetry of Luis Cernuda)

\author{
SERGIO NAVARRO RAMÍREZ \\ snavarro.3@alumni.unav.es \\ Universidad de Navarra
}

Fecha de recepción: 10 de agosto de 2016

Fecha de aceptación: 15 de junio de 2015

Resumen: Este artículo estudia las distintas nociones y experiencias del tiempo en la poesía de Luis Cernuda posterior a la Guerra Civil española. El poeta sevillano elabora en sus poemarios diferentes mitos sobre el tiempo, buscando una temporalidad alternativa a la cronológica o a la histórica. Esta búsqueda está lejos de ser un mero juego intelectual, puesto que nace de una necesidad personalísima del poeta: la de superar la traumática experiencia del exilio. Así, veremos que las constantes y preocupadas reflexiones cernudianas sobre el tiempo buscan, en el fondo, una respuesta o una solución a los hechos de su biografía, descubriendo la conciencia temporal en el núcleo de las demás preocupaciones del poeta.

Palabras clave: Luis Cernuda. Exilio. Fenomenología del tiempo. Memoria. Guerra Civil española.

Abstract: This essay studies the experience of time in the poetry that Luis Cernuda composed after his exile during the Spanish Civil War. The poet imagines in his work temporal myths that attempts to create a new temporality, different from chronological or historical time. This search is not a mere intellectual exercise; on the contrary, it emerges from a personal need of the poet: that of overcoming the traumatic experience of the exile. Therefore, we will see that Cernuda's frequent and worried reflections on time look for an answer or a solution to this fact of his biography, discovering that the time consciousness lies in the heart of the poet's concerns.

Key words: Luis Cernuda. Exile. Phenomenology of Time. Memory. Spanish Civil War. 


\section{Introducción}

Es un lugar común señalar que los temas principales de la lírica son el amor y la muerte. Este último, en realidad, enlaza con un universo de quizá mayor presencia en la literatura, que es el de la preocupación por el tiempo. El tópico crítico del tempus fugit es más que un motivo literario, es casi un rasgo del género, pues su presencia en la historia de la poesía es constante e intensa. Muchos críticos y poetas han escrito sobre la íntima relación entre la poesía y la vivencia de la temporalidad.

Nuestro siglo XX, tan escéptico de los grandes temas ya desde el dadaísmo y La deshumanización del arte, nunca ha abandonado esta preocupación poética y los testimonios de lírica que se construye sobre el tempus fugit son casi inagotables. Y, no obstante, nombro el tempus fugit con reticencias. Porque, en algunos casos, descubrir que lo bello pasa es normalmente solo el primer movimiento hacia la búsqueda de un tiempo distinto, donde lo bello permanece (piénsese en un Machado, un Guillén, un Rodríguez o, hoy día, un Sánchez Rosillo...). De esta búsqueda surgen ideas, proyectos y filosofías que intentan fundar una temporalidad distinta, donde la permanencia sobrevive a la fugacidad. El objetivo de este ensayo es estudiar este movimiento en la poesía en Luis Cernuda.

En estos momentos, Zubiaur o algún discípulo se estará llevando las manos a la cabeza al encontrarse una lectura de la poesía del sevillano que subraya la relevancia de lo temporal en ella, pues para el crítico la preocupación del poeta por el tiempo era sólo tangencial, escenario de otras preocupaciones (2002: 31). Por otra parte, autores como Molina, Silver o Harris han comentando sobre la presencia de la conciencia de lo temporal en la producción cernudiana. Sin embargo, su acercamiento a la cuestión no aborda toda la profundidad y complejidad del asunto: o es tangencial y esquemático o consideran la temporalidad como un fenómeno más y, a la larga, como un telón de fondo, que es lo que Zubiaur defiende. Espero desarrollar aquí un estudio más detallado de esta dimensión de la obra de Cernuda para demostrar que la temporalidad se encuentra en la raíz misma de los grandes problemas que Cernuda trata en su lírica y que, naturalmente, si lo primero es cierto, la solución a estos problemas pasa por fundar una temporalidad distinta a la que los genera. Por ello, considero necesario un tratamiento de la cuestión mucho más detenido y detallado que lo que se ha hecho con anterioridad.

\section{La memoria del niño}

Es bien conocido que la palabra "texto" procede del latín "texere", que significa "tejer". El texto sería la urdimbre donde quedan entrelazadas las 
distintas hebras de las frases e ideas que lo configuran. Pero la metáfora textil no es exclusiva para la literatura. Los clásicos también imaginaron la vida como un tejido: las Parcas eras las divinidades que urdían y cortaban el hilo de nuestras vidas.

Esta constelación de metáforas ilumina el sentido del libro que Luis Cernuda publica en 1942, Ocnos, pues el personaje que da nombre a esta colección de poemas en prosa es, precisamente, un tejedor mitológico. Como explica el pasaje de Goethe que abre el poemario, Ocnos habita en el Hades y su infernal tarea consiste en trenzar juncos. Nada infernal sería esto si no fuese porque un asno a su lado devora vorazmente los juncos que Ocnos va trenzando. Al igual que ocurre con otros trabajadores del inframundo, Ocnos está condenado a no finalizar nunca su tarea: sus esfuerzos representan la futilidad de los afanes humanos. El hecho de que la actividad de Ocnos sea la del tejer o trenzar hace que el símbolo escogido por Cernuda sea mucho más denso que el de Tántalo o Sísifo, debido a la multitud de connotaciones simbólicas que enriquecen la actividad textil.

Así, la figura de Ocnos puede interpretarse como otros tejedores mitológicos. Trenzar juncos equivale al tejer de las parcas, es decir, el enhebrar el hilo de la vida. De la misma forma que el asno se alimenta de los juncos de Ocnos, el tiempo devoraría inmediatamente los momentos vividos. El pasado queda reducido irremediablemente a unas migajas en la boca del animal, a prácticamente nada.

Esta interpretación del título de la obra gana fuerza si se tiene en cuenta que, precisamente, Ocnos es un libro de memorias que nace, naturalmente, del recuerdo de la niñez y la adolescencia del poeta desde el exilio en Inglaterra. Decir, no obstante, que aquellos días de juventud fueron tiempos felices (el manido tópico de la infancia como paraíso perdido del que la crítica cernudiana se nutre) es una exageración. El encanto del pasado no viene determinado por la felicidad de las vivencias, sino por un sentimiento muy distinto, que el mismo poeta encuentra difícil de definir. En "La poesía", el niño Cernuda intuye algo misterioso mientras escucha la melodía del piano que proviene del salón: "entreví entonces la existencia de una realidad diferente de la percibida a diario, y ya oscuramente sentía [...] que algo alado y divino debía acompañarla y aureolarla [...]" (2003: 13). "El tiempo" también recoge una experiencia semejante, esta vez en el patio de la casa, donde presiente "[...] la vida misteriosa de las cosas [...]" (2003: 30). El motivo volverá a aparecer en "Mañanas de verano": "Parecía como si sus sentidos [los del niño] [...], fueran instrumento tenso y propicio para que el mundo pulsara su melodía rara vez percibida [...] sentirse en acorde con la vida" (2003: 39-40). 


\section{SERGIO NAVARRO RAMÍREZ}

Los ejemplos reunidos expresan un estado especial que goza el niño, que podría caracterizarse como una peculiar capacidad de visión o intuición que descubre algo misterioso y superior en la realidad que le rodea. El niño, y luego el poeta, apenas logran aclarar qué es lo percibido, y por eso en el texto aparecen términos que cifran la ambigüedad de los sentidos, como "oscuramente" o "entrever". Pues lo escondido no se revela al niño con magnificencia y esplendor, sino que se sugiere borrosamente, casi ya desvanecido, dejando tras sí la duda de si fue epifanía o producto de la soñadora imaginación de un niño solitario.

Este estado de ensoñación, o imaginación tal y como los románticos ingleses la concibieron, otorga al pasado un valor más alto que el de la propia felicidad. Esto lo explica Bachelard en La poética del espacio, donde el crítico defiende que la casa en la que pasamos nuestros primeros años permanece viva en el alma porque, precisamente, es el lugar donde el niño sueña, fantasea, imagina (Cfr. 2014: 28-31). La casa ofrece al niño un refugio para la ensoñación, convirtiéndose por ende en el lugar propio de esta actividad. Entonces el hogar, cálido y seguro, se configura en nuestra memoria como un "paraíso terrenal de la materia"1 (2014: 29).

El "mecanismo" psicológico descrito por Bachelard parece avalar la interpretación tradicional que afirma que la infancia es un paraíso perdido, no porque sea un estado de felicidad, sino de imaginación. Uno de los críticos más influyentes del poeta, Philip Silver, señala que "Albanio, como Cernuda se llama a sí mismo, existe en comunión con la naturaleza en un Edén intemporal. La muerte y el tiempo no tienen parte en él" (1995: 21). Silver entiende aquí que el Paraíso solo puede darse fuera de la conciencia del tiempo y que solo la fantasía de un niño en esa estrecha relación con la naturaleza puede vencer la angustia que el tempus fugit provoca. Comparte opinión Luis Antonio de Villena cuando afirma que "el poeta pierde el edén [...] cuando es consciente del tiempo" (1977: 143). Algunos poemas en prosa de Ocnos parecen efectivamente confirmar la teoría del crítico, pues en ellos la ensoñación infantil descubre un momento de plenitud en el que se entra a formar parte de una realidad trascendente, ajena al flujo temporal. "He visto cómo las horas quedaban inmóviles, suspensas en el aire, tal la nube que oculta un dios, puras y aéreas, sin pasar". "El tiempo" (2003: 30). Y "Ella [la belleza] ${ }^{2}$ y su contemplación son lo único que parece arrancarnos al tiempo durante un instante desmesurado". "El enamorado" (2003: 67).

${ }^{1}$ Todas las traducciones de libros que figuran en la bibliografía en inglés son mías.

2 [Añadido]. 
Sin embargo, la temporalidad que articula Ocnos es más compleja. Para explicarla, conviene acercarse al poema "La eternidad", cuyo título ya anuncia la importancia que tendrá en este asunto. Como le pasaba a Unamuno de pequeño según nos revela en Del sentimiento trágico de la vida, Albanio es un niño preocupado por la eternidad, el 'tiempo ilimitado'. Acaba el poema:

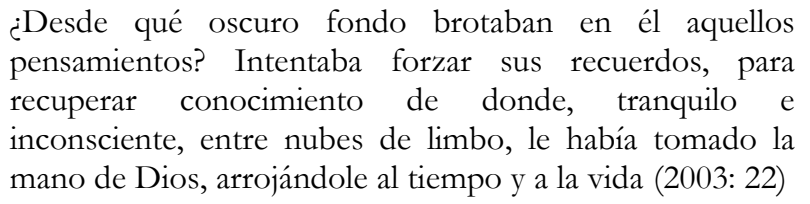

Que Albanio se pregunte por el tiempo no cuestiona la interpretación de Silver y Villena, ya que eso sólo significaría que el niño está convirtiéndose en adulto. Lo que resulta llamativo es, en cambio, que el niño se vea así mismo como un exiliado de una existencia anterior, más plena y, no por casualidad, atemporal. Albanio refleja así las mismas preocupaciones que atormentan a su yo adulto: el exilio de sí mismo. Ciertamente, Cernuda reflexiona en muchos otros poemas sobre su condición de exiliado de su propia niñez. Pensemos, por ejemplo, en el poema "Río", por seguir en Ocnos. El poeta observa desde la orilla del río a un joven remero que enciende su deseo y provoca luego esta reflexión: "El amor escapa hacia la corriente verde, hostigado por el deseo imposible de poseer otra vez, con el ser y por el ser deseado, el tiempo de aquella juventud sonriente y codiciable" (2003: 113). El amor lo entiende Cernuda como el deseo de poseerse a sí mismo de nuevo, el de unirse con el yo más joven y recuperar de esta forma la juventud perdida. El deseo es narcisista. Más tarde, con poemas como "Luis de Baviera escucha Lohengrin" confirmaremos esta intuición.

También el niño se siente exiliado de sí mismo, como si Dios le desarraigara de una existencia más feliz y lo arrojase a un mundo devorado por la rapacidad del tiempo. Desde el tempus fugit, el niño aspirará a un mundo más estable. Puede leerse en "Escrito en el agua": "Desde niño, tan lejos como vaya mi recuerdo, he buscado siempre lo que no cambia, he deseado la eternidad" (1970: 197). En el fondo, Cernuda intuye aquí que los momentos de trascendencia o casi intemporalidad gozados en la niñez sólo eran el producto de su imaginación infantil. Pero además, como hemos visto, "La eternidad" trasladaba la sensación de exilio del adulto al niño. Estos dos movimientos sugieren la negación de la existencia fáctica de una edad de oro, de un paraíso perdido, que es más bien un esquema mental con el que observamos nuestra 
vida, sin importar la edad desde la cual echemos la vista atrás. "Cualquiera tiempo pasado / fue mejor", como ya dijo Manrique.

A esto se refiere precisamente Paul Ricoeur en Memoria, historia y olvido cuando afirma que nuestra percepción del pasado está casi inevitablemente "modificada" por el presente desde el que recordamos (Cfr. 2004: 32). La memoria es una lente de color que tiñe lo visto a través de ella con un brillo especial, "edénico" en el caso de Cernuda, que no se encuentra en el objeto mismo, sino que es proyección del sujeto que añora.

"Río" y "La eternidad" pertenecen a una amplia sección de la obra cernudiana donde la idea del exilio de sí mismo resulta predominante. En ellas, el adulto que escribe sufre una alienación respecto a su niñez y juventud. En esto el poeta coincide con Jung, cuando el psicólogo afirma en Los arquetipos y el inconsciente colectivo: "las experiencias visionarias de este tipo" - es decir, "la visión de uno mismo [...] como un niño" - "dependen, como sabemos, de que haya tenido lugar una disociación entre el pasado y el presente" (1975: 162). La visión del niño señala la separación que existe entre él y el adulto, entre el poeta y su recuerdo. Como el río de Heráclito, al que el "El río" naturalmente alude, nunca somos el mismo que el que éramos, aunque esto no impide que busquemos esa identificación, esa especie de eternidad en uno mismo que sobrevive al flujo del tiempo, un bastión de estabilidad en medio de la mutabilidad de las cosas.

La fenomenología del tiempo que elabora Ricoeur en Memoria, bistoria y olvido resulta útil para formular el problema que la poesía de Cernuda se plantea. Para el filósofo, el problema del pasado consiste en una dialéctica irresoluble entre dos formas de percibirlo: "la dialéctica principal entre el 'nunca más', que marca el carácter de transcurrido, abolido, desbancado, [del pasado] y el 'habiendo sido', que designa su naturaleza original y, en este sentido, indestructible" (2004: 498). La cuestión es que ninguna forma de percibir el pasado se impone sobre la otra y, de esta forma, el pasado aparece como perdido y, al mismo tiempo, como alcanzable. ¿Cómo si no entender la poesía de Cernuda, que aspira a la unión narcisista con su yo más joven, a la vez que lamenta su pérdida irremediable?

Esta es la lucha del poeta, que pelea contra el tiempo para que no se desvanezcan del todo los momentos felices: "Como Orfeo afrontarías los infiernos para rescatar y llevar de nuevo contigo la imagen de tu dicha, la forma de tu felicidad". "Regreso a la sombra" (2003: 150). Su lucha es la de Ocnos contra el asno. Decíamos que los juncos trenzados representaban la vida humana, siguiendo la metáfora textil clásica. Cada momento vivido es un lazo 
en el talle de la planta. Pero estos lazos solo perduran efímeramente, pues el apetito voraz del asno los devora.

Salvar estos momentos significaría lograr la estabilidad del yo, donde el "habiendo sido" del pasado superase al "nunca más". Cernuda "habría sido" el niño: la unión narcisista culminaría en la plena identificación del yo con su pasado. Cernuda primero intenta esta unión a través del recuerdo. De hecho, para Bachelard, recordar los lugares de la niñez, donde suceden muchos poemas de Ocnos como "La poesía" o "El tiempo", arriba comentados, otorga "al ser humano la prueba o la ilusión de la estabilidad" (2014: 38).

Pero, ¿cuál es el resultado de esta lucha entre el poeta y el tiempo? Existen argumentos para pensar que esta lucha tiene un resultado positivo. Así lo ve, por ejemplo, Bernard Sicot, que recientemente ha defendido la posibilidad de volver al "paraíso perdido" de la infancia: "sí hay un regreso, un poco de felicidad, pues, aunque sea mínima, en el encuentro impuesto entre memoria y realidad" (2002: 57). Desde la filosofía, Ricoeur también abre la puerta a este regreso cuando habla de cierta 'retención' del pasado, que "todavía se aferra a la percepción del momento" presente - noción inspirada por Husserl (2004: 57) y que, por lo tanto, es todavía accesible. A su vez, desde la psicocrítica, Bachelard expresa: "iCon cuánta fuerza ellos [los poetas] nos demuestran que la casa que perdimos para siempre sigue viviendo en nosotros!" (2014: 77).

A pesar de estos testimonios, la sombra de Ocnos proyecta su pesimismo sobre la batalla de Cernuda contra el tiempo, ya que Ocnos es una imagen del propio poeta. La futilidad de su trenzar representa la esterilidad de la tarea poética de la memoria, que consiste en recuperar los momentos de plenitud. Pues la escritura de los recuerdos en este poemario no logra esa estabilidad del ser, esa unión del yo pasado con el del presente. Todo lo contrario, la misma escritura implica una alienación del poeta respecto a sí mismo. Tal alienación queda representada en el niño de Ocnos. Su nombre es distinto al del poeta, quien se dirige al niño frecuentemente con un "tú", que marca la distancia, y muy rara vez bajo la formulación abarcante del "yo" (como en el primer poema). Albanio es, literalmente, un "alter ego", un "otro yo", alguien entre la alteridad y la mismidad, que abre una separación y que, al mismo tiempo, llama a la unión. En palabras de Gil de Biedma, poeta que utiliza técnicas parecidas en su propia obra, "[...] su conciencia, aunque la asume, no se reconoce en la ambivalencia de la identidad: él es el otro" (1977: 17).

En el poema "Silla de rey", de "Vivir sin estar viviendo", leemos:

Es en su celda, el fraile, donde doma el deseo;

En su campo el soldado, donde forja la fuerza; 
SERGio NAVARro RAMÍREZ

En su espejo el poeta, donde refleja el mito.

(2014: 275)

El espacio propio del poeta es el espejo, donde aparece materializada su personalidad dividida entre el yo que contempla y el yo-otro contemplado del reflejo. Así, la imagen que el poeta observa en su labor, la imagen de su niñez en el caso de Ocnos, es tan inalcanzable como esa otra imagen que miramos y nos mira al otro lado del espejo. Su distancia no impide que, como Narciso, el poeta se enamore de su imagen más joven y anhele la unión con ella, quedando como testimonio solo el eco de sus versos.

Pronto volveremos sobre esta concepción narcisista del amor en Cernuda, pero aún no hemos agotado la riqueza de estos versos de "Silla del rey". Si el espacio propio del poeta es el espejo, su tarea consiste en "reflejar el mito", es decir, el crearlo. Al escribir sobre su niñez, Cernuda ciertamente imagina el mito de un paraíso perdido, en vez de "recordarlo" propiamente. Cernuda construye su niñez, bautizando su creación con el nombre de Albanio, pues "la escritura se convierte en un proceso de autoconstrucción del sujeto" (2014: 351), como señala Insausti, aunque el crítico se refiera aquí a los monólogos dramáticos del poeta y no a Ocnos. Lo que late en el fondo de este asunto quedó ya identificado por Paul de Man en sus conocidas nociones sobre la autobiografía. De Man entiende la escritura autobiográfica como "prosopopeya", es decir, como prosopon poein, o "conferir una máscara o una cara" (1979: 926), como creación de un mito, a la larga (Ocnos y Albanio, en el caso de Cernuda). El problema consiste en que la escritura de la memoria, que intentaba anular la distancia temporal que se abría entre el yo y su alter ego, se convierte en una auténtica "modificación" del pasado, en términos de Ricoeur (2004: 32). Así, en vez de cerrar la distancia, la autobiografía la aumenta, pues el alter ego se hace más inalcanzable al situarlo tras la "máscara".

Pero, ¿por qué Cernuda busca cerrar esa distancia y consumar la unión narcisista entre el niño y el poeta? ¿Qué necesidad o urgencia impulsa al poeta desde dentro hacia esa búsqueda? Encuentro iluminadoras a este respecto las ideas que Edward Said escribe en "Sobre el exilio". Para Said, el exilio "es fundamentalmente un estado de discontinuidad del ser [...] Por lo tanto, los exiliados sienten una urgente necesidad de reconstituir sus vidas rotas" (2000: 177). Como bien sabemos, Cernuda escribe Ocnos desde el exilio en Inglaterra. Si Said acierta con su teoría, entonces Ocnos es el testimonio del poeta exiliado que quiere reconciliarse consigo mismo, sellar la grieta en su ser que la experiencia del exilio ha abierto. Para ello, Cernuda debe acometer la difícil tarea de reconciliar el pasado (el niño) con el presente (el poeta). Tal 
reconciliación puede cifrarse, en el fondo, en una negación de la distinción entre pasado y presente que abra las puertas a una nueva temporalidad.

\section{El tiempo de lo divino}

En "Regreso a la sombra" de Ocnos, Cernuda representaba la lucha del poeta contra el tiempo con la ayuda del mito órfico. Habíamos leído: "Como Orfeo afrontarías los infiernos para rescatar y llevar de nuevo contigo la imagen de tu dicha, la forma de tu felicidad" (2003: 150). El poema sigue: "Pero ya no hay dioses que nos devuelvan compasivos lo que perdimos [...]". Lo divino aparece formulado aquí como aquello que puede devolvernos el pasado perdido. Así pues, la búsqueda cernudiana de la nueva temporalidad pasa por encontrar una fuerza divina que la funde.

Lo divino supera la temporalidad del tempus fugit y abre la eternidad al poeta. Cernuda expresa esta idea en el poema "El águila", que desarrolla líricamente el mito de Zeus y Ganimedes. Zeus cumple un papel parecido al de Orfeo: si el músico se internaba en el Hades para rescatar "la forma de tu felicidad", el dios rescata a Ganimedes del flujo inexorable del tiempo:

Tú no debes morir. En la hermosura, la eternidad trasluce sobre el mundo, tal rescate imposible de la muerte. (2014: 196)

El paralelismo entre Zeus y Orfeo, pues ambos descienden al flujo de lo temporal para rescatar los momentos de hermosura, conecta al poeta con el dios. "La poesía fija la belleza efímera" (1960: 198), escribe Cernuda en "Palabras antes de una lectura", igual que Zeus eterniza la belleza de Ganimedes al elevarlo al firmamento. La poesía es el arma del poeta contra el tiempo.

La consideración de la belleza en la poesía de Cernuda es ambigua. Por una parte, debe ser rescatada del flujo del tiempo: Zeus rescata a Ganimedes. Pero, además, y casi paradójicamente, en la belleza está la capacidad de superar al tiempo y establecer esa distinta temporalidad a la que Cernuda aspira: "[...] En la hermosura, / la eternidad trasluce sobre el mundo". La belleza es divina, trascendente, eterna.

Ya en Ocnos, encontramos vislumbres de una trascendencia en la que el tiempo parece detenerse. La descripción más emocionada de esto se encuentra en el último poema, "El acorde": "El instante queda sustraído al tiempo, y en ese instante intemporal se divisa la sombra de un gozo intemporal, cifra de todos los gozos terrestres que estuvieran al alcance" (2003: 154). Estos 


\section{SERGIO NAVARRO RAMÍREZ}

instantes se relacionaban con los momentos donde la imaginación del niño es más soñadora, como sucede en "El patio" o en "La poesía". En ellos, la presencia de una realidad trascendente (o su vislumbre) "abre" el tiempo, libera al instante de la temporalidad. Pero, como ya hemos señalado, Ocnos es un libro de memorias y tales instantes vuelven irremediablemente al pasado, cuando la memoria los recuerda y el poeta los escribe, situándolos en el tiempo, ya ido.

La misma ambigüedad encontramos los poemas cernudianos que hablan de la belleza y el sentimiento que esta despierta, el deseo. En algunas ocasiones, Cernuda parece creer que la intensidad del deseo permite al momento erótico liberarse de las cadenas del tiempo. Entonces, la experiencia amorosa borra la conciencia del tiempo: "¿Quién pretende / que la dicha se mida por el tiempo?". "Elegía anticipada" (2014: 255). A su vez, en "El perfume”, poema que recuerda inevitablemente a Baudelaire y su compartida lucha contra el tiempo, Cernuda asegura que el deseo permanece "insumiso al tiempo" (2014: 168).

Sin embargo, en otros casos, la intensidad erótica pierde su predominancia y se establece un difícil equilibrio entre el poder "divino" del amor - en cuanto "eternizador", ya que, como el poema "El águila" expresa, "amor divino / sombras de espacio y tiempo pone en fuga" (2014: 196) - y la fuerza de la conciencia del tempus fugit:

Déjame amarte ahora. Un día, temprano o tarde, Dios dispone que el amante deba renunciar a su amor.

XV “Poemas para un cuerpo" (2014: 324)

Este conflicto se resuelve entonces en un hedonismo pesimista, donde la felicidad se sitúa en el goce de las bellezas efímeras, precisamente por el hecho de ser pasajeras. "Si el beso y la rosa codicio, indiferente hacia los dioses todos, / es porque beso y rosa pasan. Son más dulces los efímeros gozos" (2014: 180). Así se expresa Gaspar en "La adoración de los magos", el rey que representa precisamente al placer.

Me es imposible registrar aquí todas las modulaciones que la intersección amor - tiempo adquiere en la poesía de Cernuda. Por ello, considero más interesante centrarnos ahora en un conjunto de poemas donde la relación de lo erótico con lo temporal se convierte en el centro problemático que articula el poema, pues el amante anhela consumar la unión amorosa con un amado que habita en el pasado. Son poemas donde, en el fondo, se aspira al narcisismo. 
"Luis de Baviera escucha Lohengrin", por ejemplo, expresa en la figura del rey un deseo narcisista de unión con el yo más joven. Inmerso en una ensoñación que le provoca la música de Wagner, se le aparece al rey un joven que enciende su deseo. En medio del poema, Luis de Baviera se da cuenta de que este joven es en realidad él mismo hace tan sólo unos años:

Él es el otro, desconocido hermano cuyo existir jamás

$$
\text { creyera] }
$$

ver algún día. [...] en él ya ama

aquello que en él mismo pretendieron amar otros

[...] Pero, ¿puede

consigo mismo unirse?

(2014: 350)

La última pregunta cuestiona la posibilidad de la unión narcisista. La respuesta, en este caso, parece ser positiva:

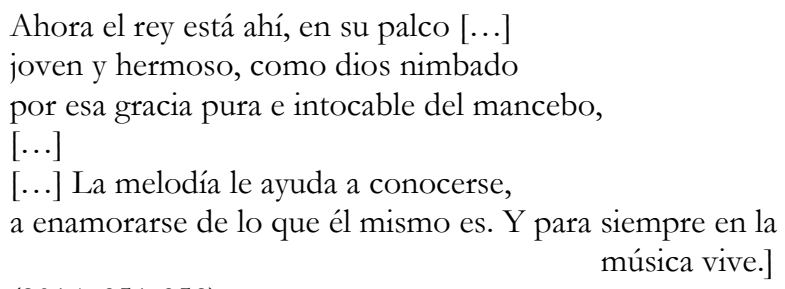

(2014: 351-352)

Como explica el final del poema, el logro de la unión radica en la temporalidad de la música. Cernuda reflexiona sobre la especial temporalidad de este arte en "La concha vacía" de Variaciones sobre un tema mexicano, donde sugiere la capacidad de la música para preservar invioladas las experiencias que vivimos mientras escuchábamos una melodía. Es interesante notar que Cernuda comparte aquí ideas con la filosofía del tiempo desarrollada por Husserl en Fenomenología de la conciencia del tiempo inmanente, donde el pensador dota a la música de una temporalidad especial, ya que su duración, al ser un objeto puramente temporal, forma parte esencial de su naturaleza, imponiendo entonces su tiempo sobre el tiempo de nuestro interior y la cronología exterior (Cfr. Ricoeur, 2004: 32-35).

En cualquier caso, la idea de "Luis de Baviera escucha Lohengrin" es clara: el amor es como la música, tiene su propia temporalidad. En virtud de este tiempo especial, una unión a priori imposible, como es el la del yo adulto del presente con el yo joven del pasado, se hace posible. El amor reconcilia el 
pasado y el presente en su "presente eterno", como le gusta llamarlo a Silver (1995: 57) o, quizá mejor si se quiere evitar la reminiscencia todavía temporal presente en la formulación del crítico, en su instante eterno.

Sin embargo, otros poemas como "Cara joven" o "La sombra" muestran un mayor pesimismo respecto al éxito de la unión narcisista. Y es que en Cernuda la conciencia del tempus fugit siempre amenazará al momento de plenitud, ya sea erótica o imaginativa. Esta amenaza establece, en el fondo, un difícil equilibrio entre el tiempo divino y el tiempo humano, entre la belleza y la muerte, que produce la ambigüedad antes señalada, representando la belleza como redentora, pero también como redimida.

Incluso los dioses padecen su crepúsculo, del que deben ser rescatados. El poeta dirige estas palabras al Cristo de "La adoración de los Reyes": "su alma / sometida al destino de las almas, / cosecha que la muerte ha de segarla" (2015: 182). Significativamente, la sección donde pueden encontrarse estos versos se titula 'Palinodia de la esperanza divina'. Tal título expresa en cierto sentido una de las crisis de las que nace la lírica cernudiana, la constatación de que incluso lo divino, aquello que podía salvarnos de la voracidad del tiempo, necesita a su vez redención frente a la muerte. Y no sólo Cristo; también los dioses paganos sufren este destino. "Resaca en Sansueña" nos narra la caída del dios protector del placer edénico de Sansueña, convertido en una estatua hundida y olvidada en el océano. El dios de Sansueña es, efectivamente, la encarnación del ideal paradisíaco descrito en la primera parte del poema: "Bellos como la luna, cadenciosos de miembros / [...] Su juventud espera. / la hermosura se precia [...]" (2014: 160), pero acaba siendo un ideal caído.

En "El poeta y los mitos", de Ocnos, Cernuda conecta expresamente divinidad y belleza. Cuando habla de la mitología helénica, afirma que "los hombres fueron tan felices para adorar, en su plenitud trágica, la hermosura" (2003: 34). El problema es lo que hemos venido señalando, que el remedio contra el tiempo es, inevitablemente, presa del fluir de las horas. Lo divino, en Cernuda, no es más que la encarnación de la belleza: frágil plenitud, dicha pasajera.

En este sentido, su poesía y su visión de la divinidad son plenamente románticas, al menos hölderlinianas - el propio Cernuda destaca la influencia del romántico alemán en Historial de un libro (2014: 398). La explicación de la esencia de la poesía en Hölderlin que lleva a cabo Heidegger me parece particularmente iluminadora en este respecto: "la poesía pertenece a un determinado tiempo [...] Es el tiempo de la necesidad, pues se funda en una doble carencia, el No-más de los dioses que han huido y el No-todavía del dios que está viniendo" (1949: 373). Esta concepción, naturalmente, es en sí misma 
romántica. Ya August Schlegel, en la primera de sus lecciones en "Arte dramático y literatura" opone la poesía romántica a la griega, pues la lírica romántica bebe de la tradición cristiana y, por eso, anhela una reconciliación entre lo visible y lo invisible, lo efímero y divino, que estaba no obstante unido en la poesía helénica (Cfr. 1973: 26).

De esta forma, la poesía de Cernuda crea la necesidad de una temporalidad que solo puede ser divina. Pero no recoge el triunfo de la divinidad sobre el tiempo, sino más bien lamenta su fracaso y posterior "huida" (pues ella también sufre la fugacidad de las cosas) y cifra la espera en un dios que sea capaz de abrir ese instante eterno.

\section{Historia de lo divino}

Esta dialéctica del tiempo poético que traza Heidegger entre el No-más y el No-todavía es, en el fondo, muy parecida a la ambigüedad del pasado que detecta Paul Ricoeur. Ambas señalan una tensión entre presencia y ausencia que articula además la poesía de Cernuda. Veíamos que, de acuerdo con Said, el exiliado tiene una necesidad de "estabilidad", de continuidad entre pasado y presente: de descubrir en su tiempo la mismidad de su yo. Pero esto requiere de una "persistencia" del yo joven en el yo adulto, sólo lograble desde una visión del tiempo en la que el presente retenga de algún modo el pasado: la victoria del "habiendo sido' sobre el 'nunca más", de Ricoeur.

Existe un momento en la poesía de Cernuda donde la continuidad del presente y el pasado se afirman sin ambages. Son estos versos de "Elegía española [П]":

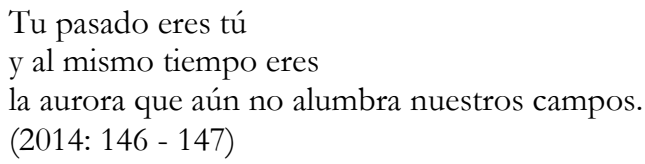

Estos tres versos expresan la mismidad de ese "tú", idéntico con su yo pasado ("tu pasado eres tú") y al mismo tiempo continuo con su yo futuro ("eres / la aurora que aún no alumbra nuestros campos", pero que los alumbrará, podría añadirse). Además, tal continuidad en el ser parece garantizar la inmortalidad al referente del "tú", ya que su futuro no es la muerte, sino un nuevo nacimiento venidero, sugerido por la metáfora de la aurora que ha de nacer sobre los campos.

A quien refiere la segunda persona de este fragmento no es ninguna persona, sino un país, España. Si los exiliados sufren un "estado de discontinuidad del ser" y necesitan "reconstituir sus vidas rotas" (Said 2000: 


\section{SERGIO NAVARRO RAMÍREZ}

177), es porque han sido arrancados de un ente que asegura en sí mismo la continuidad del ser y la constitución de la vida (teóricamente, al menos, ya veremos que esto no es exactamente asî́. Tal ser, dotado de una fuerza capaz de sobrevivir a la fugacidad del tiempo, parece divino (y más si tenemos en cuenta que en Cernuda lo divino aparece caracterizado como aquello que precisamente funda una temporalidad distinta). Por eso, no ha de extrañarnos que la poesía de Cernuda represente a España como a una deidad, como bien ha señalado Silver (1995: 246).

Cernuda, ciertamente, crea un mito de España. En "Elegía española [T]", España es "esencia misteriosa / de nuestra raza", lo que sugiere ya cierta espiritualización del país. Como una divinidad, España asume un rol creador para esta raza ("hálito creador", le llama el poeta y, posteriormente, "madre"). $\mathrm{Y}$, de hecho, el comienzo del poema se formula como una invocatio de esta musa-diosa îbera: "Dime, háblame / Tú, esencia misteriosa (...)".

En la segunda elegía española continua la divinización de España, que queda reforzada como deidad que sustenta la vida de los españoles, de la misma forma que, en la teología cristiana, todo lo que existe es sustentado por Dios:

Nada altera entre tú, mi tierra, y yo,

Pobre palabra tuya, el invisible

Fluir de los recuerdos, sustentando

Almas con la verdad de tu alma pura.

(2014: 154)

"La verdad de su alma pura" es el sustrato trascendental sobre el que la supervivencia de las almas hispanas se funda. Además, Cernuda invierte la situación del poema: en vez de ser él el poeta, su voz pasa a convertirse en "pobre palabra tuya", quedando entonces España como poeta. Las consecuencias de esta identificación son muy relevantes. Recordemos el poema "El águila": Zeus salva a Ganimedes de la consumación a la que toda belleza terrenal está destinada. Explicamos que el poema en sí era una metáfora del quehacer poético: la misión del poeta consistía en salvar lo bello efímero de la rapacidad del tiempo. Pues bien, España, como Zeus - águila, salva de la destrucción temporal a los Ganimedes españoles. Paradójicamente, España adoptaría más tarde como símbolo al águila, pero eso ya es otra historia.

Además, en la constelación de imágenes que Cernuda usa para hablar del poeta, se encuentra la imagen de Ocnos. Como también vimos, el fracaso de Ocnos al trenzar los juncos representa la inevitable alienación que supone escribir memorias en Cernuda, pues la memoria no consigue trenzar las experiencias vividas en una única forma, es decir, en la continuidad y mismidad 
de una sola vida, sino que produce una separación entre el yo que recuerda y el yo recordado. Sin embargo, España, como mejor poeta debido a su mayor divinidad, sí es capaz de lograr esa continuidad: "Nada altera entre tú y yo, / pobre palabra tuya, el invisible / fluir de los recuerdos", comienza el fragmento.

Así, la divinidad de España funda la mismidad identitaria de sus habitantes. $\mathrm{Si}$, como decía Said, los exiliados, al estar "separados de sus raíces, su tierra, su pasado [...] sienten, por ello, la necesidad de reconstituir sus vidas rotas' y sanar así su "estado discontinuo del ser" (2000: 177), entonces la situación contraria (la pertenencia al país, el arraigo en la tierra y el pasado) permite al ser humano un estado continuo del ser. Como ser divino, España abriría una temporalidad nueva que permitiría al poeta la plena identificación con su pasado y la superación del exilio de sí. Sicot coincide en este sentido con la visión de Said cuando explica de Cernuda: "Gracias a la memoria van a encontrarse, en la obra, estas dos necesidades del exiliado: la de una íntima unidad del yo, por supuesto, pero también la de una identidad, de una continuidad ligadas a la pertenencia histórica" (2002: 64). Aunque cabría señalar que no es la memoria lo que consigue saciar tal necesidad (pues, precisamente, la memoria es lo que desdobla al poeta en el espejo de la escritura autobiográfica, como un análisis de Ocnos demuestra), sino que este papel le corresponde más bien a la historia o, en todo caso, a la memoria colectiva.

Hoy día, en nuestra sociedad postmoderna, la idea del dios - nación ha sido severamente deconstruida y criticada, juzgándola como peligrosa. Sin embargo, ya antes de nuestro escepticismo y nuestra sospecha frente a este noción que parece entroncarse con un discurso fascista, Salvador de Madariaga, amigo de Cernuda y como él, exiliado, advertía en 1928 de los riesgos de tal discurso: "la idea de la nacionalidad [...] se transforma en religión, con todo el poder de elevar el alma del hombre al sacrificio [....] la nación se está convirtiendo rápidamente en una deidad irresponsable" (1931: 242). Y, en cierto sentido, es injusto reducir las ideas políticas de Cernuda a una simple divinización poética del país. La mitología de la nación es más compleja. Numerosos poemas de Cernuda critican duramente la sociedad española, de la cual el poeta siempre se sintió exiliado (léase, por ejemplo, la famosa "Poética" de 1932). Citarlos aquí nos desviaría irremediablemente del asunto que tratamos, pero basten como ejemplos aquellas elegías que el poeta compone a la muerte de algunos de sus compañeros de letras, donde la sociedad española normalmente juega un papel negativo en dicha muerte.

Lo que interesa, no obstante, es que en este doble acercamiento a la patria (divinización y crítica) opera intensamente, otra vez, la conciencia del tiempo. Lo divino en Cernuda padecía de cierta ambigüedad. Por una parte, fundaba el 
tiempo nuevo de lo trascendente, pero, al mismo tiempo, su inmortalidad no estaba garantizada y lo divino mismo sufría el fluir del tiempo. Esta paradoja afecta igualmente al dios - nación.

"Resaca en Sansueña" es un claro ejemplo en este aspecto. La primera parte del poema describe una sociedad edénica, de jóvenes muchachos que festejan y bailan alrededor de la estatua de un dios pagano que simboliza el placer, la belleza, la paz. En directa oposición, el segundo movimiento del poema asume la voz de dicha estatua, que cuenta al lector su declive hasta caer olvidada en el lecho del océano. El sol cuya amorosa gravedad mantenía unidos a la comunidad joven se hunde en las sombras del mar. La sociedad de Sansueña ya no adora los valores que encarnaba este dios, sino que han abrazado otros muy distintos (los de la violencia, el odio y el cainismo). Sansueña, obviamente, es un nombre y una forma del paraíso perdido, pero de un paraíso español, imposible de recuperar en la sociedad peninsular contemporánea al poeta. Hubo una edad de oro gobernada por lo divino, pero su dios fue incapaz de perpetuarse en el tiempo.

No obstante, no creo que Cernuda sostuviese firmemente que el pasado español fuese dorado o edénico. Críticos como Sicot se han visto sorprendidos por el hecho de que Cernuda admirase un pasado español (el de Felipe II o el de la Conquista de América) que no casa bien con su ideología a priori de izquierda o, al menos, incompatible con la derecha tradicional que admiraba igualmente ese pasado. Es cierto que Cernuda ve en algunos de estos momentos ciertos valores para él muy positivos: la unidad social bajo Felipe II, como se adivina en el poema "Silla del rey" (pues hay que tener en cuenta que el poeta sufrió las consecuencias de una fortísima desunión nacional que desembocó en la Guerra Civil), o la firmeza de un propósito espiritual en el caso de la Conquista, como sugiere el poeta en V ariaciones sobre un tema mexicano. Pero, aparte de estas posibles consideraciones, sucede aquí lo mismo que comentamos respecto a Ocnos. Es la memoria lo que "modifica" el pasado, tiñéndolo de felicidad paradisíaca: tal felicidad no pertenece al pasado en sí, al igual que para el niño su estado no es una edad de oro, aunque así lo juzgue posteriormente el adulto. El poeta elabora el mito de Sansueña o de la nación dios, como antes había forjado el mito de su niñez.

La verdadera esencia de Sansueña no es edénica, sino ambigua, esquizofrénica (en el sentido literal de la palabra, es decir, como división de la persona) y esto queda magistralmente reflejado en "Ser de Sansueña". El poema plasma literalmente un motivo literario muy común en la época: el tema de las dos Españas. Cernuda percibe la dualidad del país en su paisaje ("Árida tierra, cielo fértil [....]"), en su sociología ("La nobleza plebeya, el populacho noble") y 
en su psicología ("el amor junto al odio y a la caricia junto / a la puñalada [...]") (2014: 272). Tales contrastes señalan en el fondo un violento claroscuro entre el despreciable presente y un pasado feliz, lo cual no se formula al final como una paradoja, sino con la poderosa elocuencia del deseo ("Si en otro tiempo hubiera sido nuestra [España]") y la resignación ("Vivir para ver esto/ Vivir para ser esto").

La naturaleza de esta esquizofrenia se asemeja a la esquizofrenia del poeta cuando se siente alienado de su yo más joven: es la grieta que abre en cualquier ser (ya sea individual o nacional) la constatación de que el pasado es inalcanzable para el presente, pero de que, al mismo tiempo, su sombra todavía es visible, tentándonos con la visión de la unión y la continuidad del ser, que anhelamos profundamente. Para Ricoeur, la temporalidad de la historia es aún más radical que la de la memoria, pues "toma el pasado como pasado", mientras que la memoria aún contempla la posibilidad del "habiendo sido" y no solo del "nunca más" (Cfr. 2004: 396). Por eso, la historiografía implica una mayor alienación de sí mismo que la memoria, en cuanto que no acepta la posibilidad del "habiendo sido", o sea, del "todavía siendo". Probablemente, esta visión del filósofo sea discutible, y podría objetársele que la historia requiere de cierta continuidad en el sujeto histórico de quien se narran los hechos, aunque probablemente Ricoeur respondería que entonces hablaríamos de cierta forma de memoria colectiva bajo la cual aún se preserva la continuidad del sujeto histórico o, mejor dicho, "mnemónico".

Sea como fuere, lo cierto es que tomar lo pasado como pasado parece implicar la decisión por una actitud historiográfica en la que el sujeto que hace historia se "aleja" de un pasado que podría ser admitido como "habiendo sido", pero que es considerado, que se toma, no obstante, como "nunca más". ¿Y no es esto el primer paso hacia una separación del sujeto respecto a lo que podría ser su pasado colectivo, hacia una alienación respecto a su comunidad histórica? La historiografía (ya sea académica o, especialmente en este caso, poética) supone un modo de hacerse cargo del pasado como propio o ajeno, y esta decisión refleja una opción por la pertenencia o por el alejamiento. Tal decisión deja de ser historiográfica para convertirse en autobiográfica.

De esta forma, la esquizofrenia que sufre España en la poemas históricos y políticos cernudianos reflejan, en el fondo, el exilio del poeta. Cernuda niega a España la continuidad del ser y esta negación está preñada de consecuencias, porque, como vimos, la pertenencia al país puede redimir al exiliado y devolverlo a sus raíces. Pero para ello parece necesario que tales raíces no se arranquen del árbol, es decir, que su pasado, que forma parte del pasado español, siga formando parte del presente de España en histórica continuidad. 


\section{SERGIO NAVARRO RAMÍREZ}

Por eso, "Silla del rey", el poema que nos presenta a España como proyecto desde el punto de vista de Felipe II, concluye: "Y el futuro será, inmóvil, lo pasado: / Imagen de estos muros en el agua" (2014: 276). Anteriormente, el monarca había definido su proyecto político, que consistía en doblegar "el furor de la fiera, a quien cadenas forjo" (y que se acabaría desatando en la Guerra Civil del 36) y construir una "armonía total", que surge cuando cada persona encuentra su tarea y su sitio:

Una armonía total, irresistible, surge;

Colmena de musical dulzor, resuena todo;

Es en su celda el fraile, donde doma el deseo;

en su campo el soldado, donde forja la leyenda;

en su espejo el poeta, donde refleja el mito,

Sé que estas vidas, por quienes yo respondo,

en poco servirían de no seguir unidas

$[\ldots .$.

(2014: 274-5)

Esta perfecta cohabitación de todos los elementos de la sociedad es lo que precisamente dota de sentido a las vidas de quienes la conforman. Lo que está en clara consonancia con las ideas sobre el exilio que hemos explicado de Said: el exiliado encuentra la continuidad de su ser en la comunidad. El poema plantea posteriormente un paralelismo entre el alma y el país, siguiendo la tendencia a espiritualizar la patria perceptible en Cernuda. Felipe II afirma que su proyecto "no es piedra, sino alma", pues, como el alma, "es igual a sí misma". ¿Qué quieren decir estas palabras?

Para que el proyecto de Felipe II se lleve a cabo, para construir esa comunidad unida, España tiene que ser "igual a sí misma". El poema contesta así a la Sansueña esquizofrénica presentada en el poema inmediatamente anterior de la colección, "Ser de Sansueña". De esta forma, España debe convertirse en un "fluir no mortal de leyenda y de historia" (2014: 274), es decir, debe lograr una continuidad no interrumpida entre el pasado y el presente. Tal continuidad justifica, por ejemplo, que Cernuda utilice la figura de Felipe II para reflexionar sobre su propio tiempo, pues ambos forman parte del mismo fluir, del mismo río. Pero el poeta tiene muy presente la famosa sentencia de Heráclito que cuestiona la mismidad del río y los versos finales ("Y el futuro será, inmóvil, lo pasado: / Imagen de esos muros en el agua") aluden a ella. El deseo que encierra el primer verso está ya explicado: que el futuro sea lo pasado, que haya una continuidad que los conecte y los haga el mismo río. El 
segundo verso, no obstante, presenta la posibilidad de que tal identidad solo sea espectral: una imagen que meramente se refleja para quien la quiere ver, siendo futuro y pasado, por lo demás, de naturalezas tan distintas como el agua y la roca. Al fin y al cabo, la metáfora especular ya aparecía antes: "en su espejo el poeta, donde refleja el mito". Lo reflejado en la imagen del agua es otro mito más que Cernuda 'trenza' para conjurar la posibilidad de un retorno incierto a la continuidad. Es el mito de la continuidad de España, dividida entre una Sansueña paradisíaca y una guerra apocalíptica.

Si España es como un alma, sufre sus mismas tribulaciones. En Cernuda, la principal tribulación es la cuestión de la mismidad, la dolorosa sensación de estar exiliado de sí mismo. España padece también una esquizofrenia que divide su personalidad en la de un pasado "feliz" (o, mejor dicho, visto como feliz) y un presente miserable, el cuerpo de roca y su espectro en el agua. Y, como Narciso, corremos el riesgo de enamorarnos del reflejo, que no es, en el fondo, real, sino un mito que elabora en su tarea el poeta, mito histórico que surge, no obstante, de necesidades profundamente autobiográficas.

\section{Conclusión: el fin del exilio}

A lo largo de este ensayo, hemos estudiado la complejidad con la que Cernuda articula su conciencia del tiempo y la importancia que ésta adquiere en su poesía de exilio. En Ocnos, el pasado, conscientemente "mitologizado" como edad dorada, se muestra como inalcanzable para un yo adulto que anhela sellar esta distancia y reunirse con su alter ego, el niño. Para ello, se hace necesaria la búsqueda de una temporalidad distinta que, lejos de la cronología tradicional, permita conciliar pasado y presente en un instante atemporal, eterno. Solo lo divino, que en Cernuda adquiere la forma de la belleza y, por extensión, la del deseo amoroso, abre un momento de tal intensidad que es inmensurable en el tiempo. El problema, no obstante, consiste en que incluso para lo divino llega un fin y la belleza se marchita en el fluir del tiempo.

La segunda vía que hemos estudiado abandona la frustrada "eternidad" de lo bello y se adentra en la temporalidad de lo histórico y, concretamente, en las ilusiones de continuidad y mismidad del país, que atraen inevitablemente al Cernuda exiliado. Como la preocupación por la alienación de sí mismo parece venir de una experiencia de desarraigo y exilio, como Said diagnostica, la reintegración del exiliado en la comunidad histórica de la patria, temporalmente ininterrumpida, promete la continuidad del propio yo. El país ofrecería de esta forma una temporalidad que, distinta a la de lo bello y lo eterno, permite una reconciliación de pasado y presente en el "fluir" de la patria, como un río es el mismo en su nacimiento y en su desembocadura. Pero Cernuda igualmente 


\section{SERGIO NAVARRO RAMÍREZ}

sospecha que esto es otro mito, como el del pasado dorado, que el poeta elabora para mantener vivas unas esperanzas que nunca serán puestas a prueba en la realidad (pues Cernuda nunca volvió a España).

Encontramos, sin embargo, un momento especial en la lírica cernudiana donde estos dos caminos se juntan. El tiempo eterno de lo bello y el tiempo continuo de la comunidad coinciden en un momento, recogido en Variaciones sobre un tema mexicano. En los poemas en prosa de esta colección, Cernuda atesora la experiencia de un retorno. Aunque el poeta no vuelve a la península, el exiliado encuentra su patria en un continente lejano: "En tierra bien distante, pasados los mares, hallas trazado aquí [....] un rinconcillo andaluz". "El patio" (1977: 135). El poema describe una suerte de comunión con la naturaleza del lugar - "Viendo este rincón, respirando este aire, hallas que lo que afuera ves y respiras también está dentro de ti" (1977: 135) - y de tal correspondencia, resurgen los recuerdos del pasado que vivían perdidos en las profundidades del adulto: “ $[\ldots]$ en el fondo de tu alma [...] está la imagen misma de lo que en torno tienes; y que desde tu infancia se alza, intacta y límpida, esa imagen fundamental, sosteniendo, ella tan leve, el peso de tu vida y su afán secreto" (135).

Con el emerger de esta imagen de la niñez, que recuerda al mundo de Ocnos, se sella una reconciliación en la forma simbólica de un abrazo entre el yo adulto del poeta y su espectro, el niño: "el hombre que tú eres se conoce así, al abrazar al niño que fue, y el existir único de los dos halla su raíz en un rinconcillo secreto y callado del mundo" (135). Esta unión narcisista señala la reunión entre los dos yos en los que el poeta se sentía dividido. El "rinconcillo andaluz" acoge al exiliado; le recuerda a su patria y al devolverlo a ella transfigurada, sella las discontinuidades de su ser en un 'existir único'.

La reconciliación es, pues, doble - su abrazo abarca tanto al niño que fue como a su patria- y esta experiencia pasa a ser constituyente en la vida del poeta, pues ella sostiene "el peso de tu vida". Gadamer también concibe el ser como un retorno. Escribe en Verdady método: "buscarse a sí mismo en lo ajeno, convertirlo en la propia casa, es el movimiento básico del espíritu, cuyo ser es solo retornar a sí mismo desde lo que es otro" (1979: 15). Esta experiencia, a la que el filósofo denomina "Einhausung", es la contraria al exilio: si el exilio consiste en un salir de lo propio a lo ajeno, causando una división en el ser, el "Einhausung" permite un retorno del espíritu desde lo que en principio era ajeno a lo que le es propio, o, mejor dicho, a sí mismo, sanando la ruptura que el exilio causa. El exilio es una salida de sí mismo, mientras que el "Einhausung" es el retorno a sí mismo: división y reconciliación, 
respectivamente. Así, el núcleo de Variaciones sobre un tema mexicano consiste precisamente en una experiencia de "Einhausung".

El motor del "Einhausung" no consiste en una semejanza entre los paisajes: no es la naturaleza mexicana lo que consigue despertar las imágenes de la niñez (¿qué parecido puede haber entre la geografía española y la mexicana?). Lo que provoca esta experiencia es el amor: "En un abrazo sentiste tu ser fundirse con aquella tierra; a través de un terso cuerpo oscuro [...] alcanzaste la unión con aquella tierra que lo había creado". "La posesión" (1977: 137). En Historial de un libro, se alude a este poder de la experiencia erótica: "Y sólo el amor alivió ese afán, dándome la seguridad de pertenecer a una tierra, de no ser en ella un extranjero, un intruso" (2014: 418). Por otra parte, en el décimo poema de la serie "Poemas para un cuerpo", que nace precisamente de la misma experiencia mexicana que narra Variaciones, Cernuda identifica la patria y su comunidad con el amante:

\author{
¿Mi tierra? \\ Mi tierra eres tú \\ $[\ldots]$ \\ ¿Mi gente? \\ Mi gente eres tú \\ (2014: 320)
}

Tal identificación no es una hipérbole metafórica sin ningún contenido real o histórico. Al leerlo con Variaciones, "Mi tierra eres tú" no significa que el poeta estará en casa siempre que esté con el amado, sino que el amado abre la puerta del retorno al exiliado, trayéndole de vuelta a su patria, que no es un estado espiritual de acogida y seguridad, sino una verdadera pertenencia política y social. En "Un jardín", Cernuda conecta con el resto de personas gracias a su propia experiencia erótica: "piensas como tuya una historia que no fue tuya" (1977: 130). La entrada a la comunidad queda además resaltada, pues el poema que precede a "Un jardín", "El mercado", recoge la experiencia contraria: "Sintiéndote intruso, y nostálgico de abandonar el lugar, te dirigiste con una pregunta a una de aquellas figuras [la gente del mercado]. Mas era un pretexto para entrar, para quedar sutilmente en el cuadro con ella". "El mercado" (1977: 131).

Silver sugiere que "La realidady el deseo narra la persistente búsqueda de una existencia ideal de unión perfecta entre el yo y el mundo" (1973: 2). Sin embargo, en la poesía de Cernuda, hallan voz otras tensiones propias de su momento histórico, que priorizan una unión distinta: la del ser consigo mismo 
y la del exiliado con su patria, que no son totalmente independientes. Cuando el poeta abraza a su amante en "La posesión", los tiempos del amor y de la patria confabulan para crear un momento en el que el retorno del exiliado se completa. Se recupera la patria, entrando a formar parte entonces de una comunidad, pero también se reconcilia con el niño que fue. El abrazo de los amantes en "La posesión" es, en el fondo, el mismo abrazo que une al adulto con el niño en "El patio". Esta unión narcisista representa una reconciliación que pone fin al estado de "discontinuidad del ser" que, de acuerdo con Said, el exiliado sufre, y sacia su necesidad de "Einhausung", de volver a la patria, aunque sea desde lo ajeno. Y así, el 'tiempo de necesidad' del que hablaba Heidegger queda superado por un instante eterno donde el poeta se reencuentra con sus dioses.

\section{Referencias bibliográficas}

Álvarez MÉnDEZ, Natalia, "Tópicos poéticos en la prosa de creación de Luis Cernuda: del paraíso perdido a la ciudad estéril”. En: Nostalgia de una patria imposible. Estudios sobre la obra de Luis Cernuda. Madrid: Akal, 2005.

BACHELARD, Gaston, The poetics of Space. Trad. por M. Jolas. New York: Penguin Books, 2014.

CernudA, Luis, "Palabras antes de una lectura". En: Poesía y literatura I. Barcelona: Seix Barral, 1960.

-, "Escrito en el agua". En: Crítica, ensayos y evocaciones, ed. por L. Maristany. Barcelona: Seix Barral, 1970.

—, "Poética". En: Crítica, ensayos y evocaciones, ed. por L. Maristany. Barcelona: Seix Barral, 1970.

—, Ocnos, seguido de Variaciones sobre un tema mexicano. Madrid: Taurus, 1977.

—, Ocnos. Madrid: El País, 2003.

—, La Realidad y el Deseo. Madrid: Alianza Editorial, 2014.

CURRY, Richard K., "Between Platonism and Modernity: The Double "Fall" in the Poetry of Luis Cernuda". En: The Word and the Mirror: Critical Essays on the Poetry of Luis Cernuda. Rutherford: Fairleigh Dickinson University Press, 1989.

De La Fuente García, Mario A., "Polifonía e ideología: diferentes voces en la poesía de Luis Cernuda". En: Nostalgia de una patria imposible. Estudios sobre la obra de Luis Cernuda. Madrid: Akal, 2005.

DE MAN, Paul, “Autobiography as De-facement”. En: $M L N$, vol. 94, 1979, pp. 919-930.

GADAMER, Hans-Georg, Truth and Method. Trad. por W. Glen-Doepel. London: Sheed and Word, 1979. 
GIL DE BIEDMA, Jaime, “Como en sí mismo, al fin”. En: 3 Luis Cernuda. Sevilla: Secretariado de Publicaciones de la Universidad de Sevilla, 1977.

HARris, Derek, Luis Cernuda: A Study of the Poetry. London: Tamesis Book Limited, 1973.

Heidegger, Martin, "Hölderlin and the Essence of Poetry". En: Existence and Being. London: Vision Press, 1949.

INSAUSTI, Gabriel, La presencia del romanticismo inglés en el pensamiento poético de Luis Cernuda. Pamplona: Eunsa, 2000.

- "Apostrofar una ausencia: los poemas dedicados de Cernuda". En: Luis Cernuda. Perspectivas europeas y del exilio. Madrid: Ediciones Xorki, 2014.

Jung, Carl Gustav, The Archetypes and the Collective Unconscious. Trad. por R.F. Hull Londres: Routledge and Kegan Paul, 1975.

LOGAN, Aileen, "Memory and Exile in Las Nubes, Como quien espera al alba and Vivir sin estar viviendo by Luis Cernuda". En: Forum of Modern Languages Studies, vol. 42, no 3, 2006, pp. 298-314.

MADARIAGA, Salvador de, Englishmen, Frenchmen, Spaniards. An Essay on Comparative Psychology. London: Oxford University Press, 1931.

MOLINA, Ricardo, "La conciencia trágica del tiempo, clave esencial de la poesía de Luis Cernuda”. En: Luis Cernuda. Madrid: Taurus, 1977.

PAZ, Octavio, “La palabra edificante”. En: Luis Cernuda. Madrid: Taurus, 1977.

Ricoeur, Paul, Memory, History, Forgetting. Trad. por K. Blamey y D. Pellauer. Chicago: University of Chicago Press, 2004.

SAID, Edward, "Reflections on Exile". En: Reflections on Exile and Other Literary and Cultural Essays. London: Granta Books, 2000.

SCHLEGEL, Augustus William, Courses of Lectures on Dramatic Art and Literature. Trad. por J. Black. New York: AMS, 1965.

SICOT, Bernard, Exilio, memoria e historia en la poesía de Luis Cernuda. Madrid: Fondo de Cultura Económica de España, 2002.

SILVER, Philip, Luis Cernuda: el poeta en su leyenda. Madrid: Castalia, 1995.

VILLENA, Luis Antonio, "La rebeldía del dandy en Luis Cernuda". En: 3 Luis Cernuda. Sevilla: Secretariado de Publicaciones de la Universidad de Sevilla, 1977.

ZUBIAUR, Ibon, La construcción de la experiencia poética en la poesía de Luis Cernuda. Kassel: Edition Reichenberg, 2002. 